\title{
LO INDÍGENA Y LA ETNICIDAD EN LAS ACTUALES PRODUCCIONES DE VÍDEO-ARTE
}

\author{
The indigenous and ethnicity in current vídeo art productions \\ O indígena e a etnicidade nas produções de vídeo-arte actuais
}

Carmen Gaona Pisonero

Professor Contratado, Universidad Rey Juan Carlos (UJRC-Madrid Spain)

carmen.gaona@urjc.es

\begin{abstract}
Resumo
Depois do esquecimento nas configurações acadêmicas da etnia, principalmente em contextos europeus, muitos dos atuais arranjos museológicos e distribuições de suas produções em vídeo nos lembram da necessidade de ressignificar o indígena, para além do conquistado e colonizado, mas sem negar e deixar perceber. a geopolítica múltipla e diversa dos povos indígenas. Por isso, neste texto é considerada fundamental uma aproximação com a realidade atual dos indígenas a partir "do visual". Especificamente, será refletida a investigação das narrativas audiovisuais de dezenove videoartistas bolivianos. A partir dos resultados desta pesquisa, defende-se a tese de ver as artes visuais como produtoras de novos líderes etnopolíticos, com uma proposta sem feridas e sem ódio histórico: uma memória visual serena, mas performática, da memória histórica.
\end{abstract}

Palavras-chave: Comnicaçâo e paisagem. Líderes de opinião pública. Etnicidade.

\begin{abstract}
After oblivion in academic settings of ethnicity, especially in European contexts, many of the current museum arrangements and distributions of their video productions remind us of the need to re-signify the indigenous, beyond what is conquered and colonized, but without denying and leaving to perceive. the multiple and diverse geopolitics of indigenous people. That is why in this text an approach to the current reality of the indigenous from "the visual" is considered fundamental. Specifically, the investigation of the audiovisual narratives of nineteen video artists from Bolivia will be reflected. Based on the results of this research, the thesis of seeing visual art as a producer of new ethnopolitical leaders is defended, with a proposal without wounds and without historical hatred: a serene, but performative, visual memory of historical memory.
\end{abstract}

Key words: Communication and Landscape. Public opinion leaders. Ethnicity. 


\section{Resumen}

Tras el olvido en los escenarios académicos de la etnicidad, en especial en contextos europeos, muchas de las gestiones y distribuciones museísticas actuales desde sus videoproducciones, nos recuerdan la necesidad de resignificar lo indígena, más allá de vencidos y colonizados, pero sin negar y dejar de percibir las geopolíticas múltiples y diversas de lo indígena. Es por ello que en este texto se considera imprescindible una aproximación a la realidad actual de lo indígena desde "lo visual". En concreto, se reflejará la investigación de las narrativas audiovisuales de diecinueve video artistas de Bolivia. De los resultados de dicha investigación, se defiende la tesis de ver el arte visual como productor de nuevos líderes etnopolíticos, con una propuesta sin heridas y sin odios históricos: un sereno, pero performativo recuerdo visual de la memoria histórica.

Palabras clave: Comunicación y Paisaje. Líderes de Opinión Pública Etnicidad.

\section{INTRODUÇÃO}

Nuestra unidad de análisis se centra en las nuevas figuras de líderes de opinión, localizadas en contextos artísticos latinoamericanos. Es innegable la pluralidad discursiva derivada del arte político o del llamado arte social, si bien nos alejaremos de forma consciente, de aquellas prácticas que tienen una directa declamación de resistencia: que evidencian y denuncian los conflictos culturales, las discriminaciones persistentes hacia grupos minoritarios o -entre otros temas más- el peso alienante de la globalización. Estas últimas no conforman nuestras narrativas de análisis, pese a su indiscutible relevancia. A nivel metodológico, queremos ocuparnos de aquellas que ofrecen una nueva mirada del colonialismo. Las obras artísticas seleccionadas y analizadas reflexionan sobre" heridas" que todavía no están cerradas y deben repensarse; también configuran nuevas voces al margen del persistente etnocentrismo. En su conjunto reflejan los diálogos Norte-Sur desde las propias voces indígenas. No obstante, pese a esa delimitación de nuestra unidad de observación, nos situamos también en un plano de poder y en las geopolíticas del arte.

En un segundo objetivo, este texto señala otro nuevo actor social de la diferencia: los video-artistas. En los discursos existentes sobre los agentes o actores que etnifican cualidades socioculturales, se tiende a catalogar como tales agentes a líderes indígenas, arqueólogos, etnohistoriadores y también a antropólogos, mezclando en este listado la mera teorización y el compromiso político consciente. Por tanto, una pregunta básica es: si ciertas prácticas videoartísticas abren nuevos procesos etnopolíticos de diferenciación. En ese último caso, puesto que nos centramos en la generación de opinión pública desde la propia obra de vídeo- 
artistas bolivianos desde la cultura indígena, estaríamos en el plano de un sujeto étnico para la política (Morales, H. 2016, p. 185).

\section{DESENVOLVIMENTO}

Los procesos de etnificación de las prácticas artísticas protagonizadas por un grupo de artistas bolivianos, son el eje vertebral de nuestra reflexión y análísis. En concreto, nos basaremos em la obra de los siguientes artistas: Joaquín Sánchez, Narda Alvarado, Rodrigo Rada, Claudia Joskowich, Alejandra Delgado, Alejandra Alarcón, Alejandra Andrade, Serena Vargas, Galo Coca, Eduardo Ribera, Alejandra Dorado, Narda Alvarado, Alfredo Román Bulacio, Roberto Unterladstaetter, Rodrigo Bellot, José Ballivián, Iván Cáceres, Aruma Sandra de Berduccy, Santiago Contreras y José Arispe.

Una vez presentado nuestra unidad de observación, cabe una previa consideración: éstos no constituyen un grupo, una corriente o escuela en sí. No obstante, pese a la diversidad formal y temática existente entre ellos, detectamos un común denominador que todos ellos poseen, y es por ello que a nível metodológico, conforman una unidad de obsevación: se expresan sin límites conscientes de las heridas creadas por la colonización. Para entenderlo reproducimos las palabras de Ramiro Garavito:

\footnotetext{
"Todos estos artistas se caracterizan -a diferencia de muchos otros artistas jóvenes- por estar conscientes de que lo que hacen es arte contemporáneo, no en un sentido cronológico, sino ideológico, por eso todos asumen un arte multirreferencial donde los límites pierden su sentido categórico, lo que es determinante para el surgimiento del video-arte "(VVAA, 2010, p. 123).
}

Cabe insertar una precisión pues, aunque nos centremos en el videoarte, los artistas de los que hablaremos y desde los que hemos reformulado el concepto de indígena/etnicidad, no son video-artistas sino por encima del medio son artistas que privilegian las indagaciones conceptuales; se identifican por tanto más allá del formato, para reconocerse en lo ideológico. Del mismo modo, en el arte contemporáneo hoy en día un artista no es encasillable en un único formato.

\subsection{Niveles de etnicidad}

En una necesaria delimitación conceptual, presentaremos qué entendemos por lo indígena, lo que nos lleva a su identificación étnica, teniendo presente la imposibilidad de separar los procesos de construcción identitarios de las siguientes categorias: la autoadscripción étnica y las culturas indígenas. De ahí que para empezar a definir lo indígena, 
precisemos antes hablar de etnicidad. Para ello, cabe presentar desde qué delimitación conceptual entendemos la etnicidad, teniendo en cuenta sus diversas y discrepantes percepciones tanto teóricas como contextuales. No olvidemos, como desde la visión europea C. Taylor $(2003 ; 51)$ la etnicidad es reemplazada por lo étnico, y su episteme se hace desde el nacionalismo romântico, con figuras como J. G. von Herder que atribuye a cada nación unos rasgos comunes e inmutables a lo largo de la historia.

"El nacionalismo cultural o étnico siempre incluye algunos elementos descendientes de las generaciones previas e ideas de una conexión cultural entro los miembros de la nación, sus antepasados y frecuentemente con un lenguaje común así nacionalidad es hereditaria. El Estado deriva la legitimidad política de su estatus como hogar del grupo étnico, protector del grupo nacional y facilita la vida social y cultural" (Gunderman, H. 1997, p.69).

Sin entrar en las particularidades de las distintas perspectivas y sin simplificar la reflexión hecha en la comunidad científica, nos sumamos a la clara diferenciación de escenarios que nos describe H. Morales (2016, p.186). Mientras en Europa lo "étnico" puede aludir a las antiguas nacionalidades que dieron origen a los modernos Estados-nacionales, en América Latina alude a pueblos originarios, a comunidades indígenas, grupos descendientes directos de las primeras poblaciones que habitaron el continente. Esa diferenciación va más allá de esa simplificada dualidad, pues de ella derivan la construcción de categorías desde las ópticas dominantes europeas. Surge así la categoría de "indio", e "indígena" inherentes ambas a la conquista hispánica y los procesos coloniales. En esta correlación se sitúan Díaz-Polanco, 2006; Degregori 2004; Bartolomé 2004, Boccara, 2002. También cabe mencionar a autores más críticos, que suman a esta categoría el sometimiento político y la exclusión socioeconómica. En este último grupo estarían: Stavenhagen 1992-2000, 2001; Foerster 1999; Bello 2004; Hopenhayn 2005 y Vergara et al. 2013); todos ellos coinciden en la gran carga etnocentrista europeísta-occidental de la demarcación conceptual "biopolítica" de la etnicidad. No es de extrañar entonces que desde nuestros imaginarios europeos, no hablemos de etnia europea, ni de la etnia inglesa o española pongamos por caso, pues la construcción de la diferencia se hace desde un grupo dominante tipificador excluyente a la diferencia.

Imposible unificar tanto en una única definición. Además, a nivel situacional, nos movemos en una móvil y adaptable perspectiva, pues y tal y como señala Héctor Morales Morgado, la etnicidad "resulta ser un fenómeno muy complejo, que tiene velocidades y grados diversos, que es diferente en cada situación y que está siempre cambiando" (op.cit. p. 
196). A estas variables que resignifican el conepto de etnicidad debemos sumarle las particularidades y transformaciones epocales.

\subsection{El indigenismo en la obra pictórica boliviana: revisión histórica}

En un momento muy concreto dentro de la pintura boliviana y anterior a los artitas analizados, encontramos un arte político de reivindicación y defensa de lo indígena. Nos referimos a la obra pictórica boliviana de un grupo de autores que pasamos a recordar en el epígrafe siguiente, de forma breve y con olvidos, pues en otros épocas lo indígena tuvo su visibilidad y presencia consciente y buscada.

\subsubsection{Antecedentes}

El arte boliviano va a elaborar entre 1925 y 1950 un discurso impregnado de nacionalismo cuyas conclusiones finales elocuentes y poco satisfactorias solo van a superarse con la aparición de la siguiente generación, la de mitad de siglo, con figuras como María Luisa Pacheco. En Bolivia, la generación de artistas que maduraron en el segundo cuarto de siglo y en la cual se cuentan Arturo Borda (1888-1953), Cecilio Guzmán de Rojas (18991958), Jorge de la Reza Prudencio¹ (1901-1958), Juan Rimsa (1898-1975), Raúl G. Prada (1900-1987), Víctor Chvatal (¿-c-1953), y Marina Núñez del Prado (1910-1995). Todos ellos compartieron en forma personal ese cuestionamiento cultural a lo indígena, y cada uno a su manera le dio salida en sus trabajos, sin detenerse en las respuestas de los demás; excepto tal vez para manifestar sus desacuerdos, como hizo Borda cuando ridiculizó, en su obra Crítica de los ismos y triunfo del arte clásico, al estereotipo indio creado por Cecilio Guzmán de Rojas. Por eso, no puede hablarse con propiedad de una generación unificada en su visión social, en sus objetivos artísticos, en sus aspiraciones intelectuales ni en sus ideas espirituales. Más bien se trató de un grupo de artistas que coincidieron generacionalmente (si bien Borda hizo su aparición antes y Rimsa tardíamente) y compartieron a tramos algunas preocupaciones, dejando percibir sus conflictos y limitaciones por la ausencia de principios sólidos que disminuyeran los efectos negativos de sus debilidades formativas, técnicas y teóricas en diferentes casos, pero que conscientes intuitivamente de dichas limitaciones supieron compensarlas en gran parte con su apasionamiento. Naturalmente a este período

\footnotetext{
1 Jorge de la Reza Prudencio (Bolivia, 1901-1958). Su indigenismo -con figuras que muestran el dolor, la angustia y la soledad- está más volcado hacia los puros valores cromáticos que hacia las estilizaciones o deformaciones. Aunque de extensa producción, su obra ha ido quedando un tanto olvidada.
} 
pertenecen muchos otros artistas que llegaron todavía menos lejos o en forma refleja sintieron la influencia de los arriba mencionados, como por ejemplo Teófilo Loayza y Humberto Bedregal, parte de cuya obra no escapa a la influencia estilística de Cecilio Guzmán de Rojas.

Es destacable como la mayoría de los artistas plásticos bolivianos de segundo cuarto del siglo XX, como Arturo Borda (1888-1953), Cecilio Guzmán de Rojas (1899-1958), Jorge de la Reza Prudencio (1901-1958), Juan Rimsa (1898-1975), Raúl G. Prada (1900-1987), Víctor Chvatal (¿-c-1953), y Marina Núñez del Prado (1910-1995) compartieron en forma personal ese cuestionamiento cultural, tuvieron una actitud crítica y revisionista con el proceso colonial, alejados del lamento y de la condena. Todos ellos intentan visibilizar y mantener vivas las culturas indígenas y su reivindicación. A diferencia de ciertos intelectuales de la época como Alcides Arguedas (Pueblo enfermo, 1909) cuya obra se construye desde el olvido de las culturas indígenas en la constitución de la nacionalidad boliviana.

\subsection{Agentes sociales de la diferencia desde las poéticas del videoarte}

En líneas generales la temática principal de los artistas analizados gira sobre dos aspectos. Por un lado, encontramos obras que introducen en la producción cultural una reflexión que provoca cuestionar y desarmar las definiciones de los significados de "lo femenino" (Paz, Valeria, 1998). Como segunda temática, destacamos el paisaje del imaginario colectivo andino.

En Los mitos profundos de Bolivia, Guillermo Francovich (1987, p.47) señala las obras de Marina Núñez del Prado (1910-1995) y de María Luisa Pacheco (1919-1982) como portadoras de dos mitos que subyacen en el imaginario del boliviano: Eternidad en Los Andes y Luz petrificada. Estas artistas, que formaban parte de un mundo cultural influenciado por el indigenismo, rescataron en su obra - de forma consciente- el vínculo del indígena con la misteriosa e imponente naturaleza. Según Francovich "las teogonías pétreas y el culto a las piedras y montañas que subyacen en el inconsciente del boliviano se manifiestan en las referencias andinas de las obras de estas artistas" (Francovich, 1987, p. 59).

Pero en la actualidad iestá presente el indigenismo en las videopoéticas bolivianas actuales? Sin ser el tema principal de la actual producción video-artística boliviana, y sin poder hablar del indigenismo videoartístico como una corriente compacta e inclusive consolidada a diferencia de la pintura boliviana, el indigenismo aparece de forma casi espontánea por no decir previsible, por el propio ritmo rizomático de la reflexión de sus artistas: 
"El video-arte hecho en Bolivia nos muestra la ratificación de esa nueva sensibilidad a partir de cual la pregunta por lo que somos no tiene ya el sello traumático de una identidad "impuesta". Sus contenidos dialogan con la aparición de nuevos sujetos y movimientos sociales que reivindican su historia; y la emergencia de nuevos contenidos en el arte como lo cotidiano, lo subjetivo, las experiencias personales, la corporalidad, el deseo, la memoria, la cultura popular, las reivindicaciones indígenas, etc., son indicadores de la pertinencia de aquella problemática planteada por la posmodernidad. En este sentido, el video-arte hecho en Bolivia manifiesta precisamente esa pertinencia, aun cuando las desventajas tecnológicas y económicas de su condición "periférica", merman de algún modo, sus posibilidades de inserción en el mainstream internacional, ávido constante de nuevos efectos, estímulos sensoriales y otras banalidades de moda". (Ramiro Garavito) ${ }^{2}$.

Es justo en esa reivindicación de elementos de la memoria histórica boliviana que los vídeo-artistas actuales hacen, que alcanzan em sus narrativas "lo indígena”. O bien, se llega a lo indígena, en esa recuperación de la cultura popular, en esa auto-construcción del artista como sujeto íntimo y cultural. Es en todos esos procesos que en definitiva, remiten a las representaciones simbólicas de unos imaginarios colectivos. El nominativo indígena toma vida. En otra línea analítica, destacamos también como lo indígena en sus obras, no son desvíos reflexivos, sino potentes y auténticos filtros reflexivos.

Así desde esta reflexión rizomática ${ }^{3}$, artistas que por ejemplo utilizan sus propios cuerpos para materializar sus ideas artísticas y reivindicaciones, haciendo de ellos auténticos campos de batalla en los que luchan por la destrucción del universo patriarcal heredado, desde esta reflexión corpórea llegan a crear geopolíticas del indigenismo. Es el caso de la obra Rapunzel ${ }^{4}(2007)$ de Alejandra Alarcón. La propia artista señala la intencionalidad de su obra, lejos de una aparente revisión prioritaria del indigenismo:

"Mi trabajo gira en torno a una preocupación sobre la identidad femenina (...) Me interesa (también) desmantelar imaginarios que sostienen a la cultura (occidental), como la mitología infantil (cuentos de hadas), las bases del imaginario creado en torno a la familia como institución legitimadora de la sociedad. Ahondar en el postfeminismo, desde el cual construyo una nueva imagen femenina empoderada en la seducción, pero también peligrosa en su maternidad castradora. " (Alejandra Alarcón. $5)$.

Sin embargo, la misma autora, en la presentación de su obra Rapunzel alude a una construcción femenina desde lo indígena y desde la presencia/ruptura del colonialismo.

\footnotetext{
${ }^{2}$ En VVAA, (2010, p. 143.

${ }^{3}$ Tomando como referente las teorías de F.Guattari y G. Deleuze.

${ }^{4}$ Disponible en Vimeo: https://vimeo.com/106187725

${ }^{5}$ En, http://conchamayordomo.com/2017/03/14/alejandra-alarcon/
} 
Dentro también de esta dinámica de la utilización de lo indígena como filtro reflexivo, mencionamos la obra de Claudia Joskowich Arrastrado y descuartizado ${ }^{6}(2007)$. En ella, se reproduce la ejecución pública en 1781 del líder de las rebeliones indígenas y héroe de los movimientos revolucionarios andinos, Tupac Katari. Éste encabezó alzamientos contra el poder colonial español y murió ejecutado por descuartizamiento. En la obra visual de Joskowich se recrea y actualiza este momento mítico-histórico en el actual paisaje boliviano. Para ello utiliza una toma panorámica entre dos motocicletas, que se mueven de izquierda a derecha, la cámara cruza una plaza de la ciudad de la Paz y se encuentra de forma casual con la ejecución. El significado de este acto violento es reprimido y sustituido por una serie de tomas construidas por los espacios exteriores que lo rodean. La ejecución, y su efecto sobre el escenario urbano son manipulados por las imágenes que ocupan la cámara y reorganizan el paisaje. En él se recrea y actualiza -usando motocicletas-, la imagen emblemática de la muerte de Tupac Katari, líder indígena en la historia colonial de Bolivia. En 1781, Katari se sublevó contra la Corona española y protagonizó una de las revueltas independentistas más importantes. Tras ser capturado fue descuartizado, y sus extremidades, -coincidiendo con escenas del vídeo- fueron repartidas por distintos lugares del territorio, como violencia real y simbólica frente a futuros levantamientos indígenas. En la obra de Claudia Joskowich, se alude a los colonizados y a los colonizadores, como tema prioritario y como recurso narrativo se integra un líder indígena de la memoria colectiva boliviana.

Pese a este ritmo rizomático que nos lleva a la reflexión de lo indígena, y a ese filtro indígena presente en las narrativas visuales de los artistas que nos ocupan, cabe destacar otras narrativas videoartísticas que aunque de forma minoritaria, su eje temático principal y punto de partida es la cultura indígena. En esta línea citamos por ejemplo a José Ballivián y a José Arispe. Este último, nos invita a pensar lo indígena, no desde la presencia física de los cuerpos o la cultura material, sino más bien desde su cosmovisión. En la obra TAYPI ${ }^{7}$ de J. Arispe, el protagonista es el propio paisaje boliviano: la Cumbre de la Paz. No en vano, en una cosmovisión andina la naturaleza, las cumbres, las montañas tienen vida, son seres. La acción de la vídeo-performance Taypi2 de Arispe se realizó cerca de la represa de Hampaturi, mediante un dron o cámara aérea se registraron cenitalmente secuencias del digamos "ritual". El vídeo queda integrado casi en su totalidad en unas recursivas imágenes en que se trenza y

\footnotetext{
${ }^{6}$ Disponible en http://archive.freewaves.org/video/drawn-and-quartered

${ }^{7}$ Ver: https://www.youtube.com/watch?v=hAE1w2rCjQU
} 
destrenza dos sogas manteniendo una nada aleatoria forma circular. Decimos "nada aleatoria", pues la circularidad de los elementos del paisaje alude a la concepción circular del tiempo en la cultura andina. La representación de la concepción circular del tiempo en los Andes ya había sido anteriormente evocada en el cine, citamos como ejemplo el plano secuencia integral de Jorge Sanjinés, en la película La nación clandestina (1989). Sin embargo, ésta es posiblemente la primera vez que se aborda el tema en el videoarte boliviano y de una manera particular: sin representación alguna de cuerpos o cultura material indígena. Arispe reflexiona sobre esta mirada del mundo:

"La proximidad a la naturaleza de las culturas originarias bolivianas nos enseña que vivimos en un universo que se equilibra y se conserva manteniendo activamente movimientos cíclicos. El tiempo no es lineal o medible, sino dinámico, orgánico y vivo. La esencia del tiempo es circular, el mundo y el universo son infinitos" (Arispe, 2018).

Otro aritsta destacable es José Ballivián, en su obra se percibe el interés del artista por reflexionar sobre el encuentro conflictivo entre la cultura material indígena y Occidente. De hecho, su trabajo contrapone lo local a lo global, tal y como podemos apreciar en sus obras La Paz (1975) y Procesión (2015). Por outro lado, en la descripción que el próprio José Ballivián hace de su obra, se resalta como eje central reflexivo la auto-construcción. Ésta es elaborada por el artista desde el uso reiterado del filtro constante de lo indígena: "En las piezas ejecutadas existe un grado de ironía, humor negro, ante el contexto en la que me voy desenvolviendo en las diferentes etapas de mi vida. Se podría decir que mi trabajo utiliza a la autoexploración como el hilo conductor" (José Ballivián, 2018). Es una autoexploración diacrónica por la historia boliviana hecha por Ballivián, desde su memoria histórica en la que por fuerza remite al pasado colonial; es entonces la autoreflexión y resignificación de lo indígena.

Este no reconocimiento temático de lo indígena em la reflexión de los artistas tratados, está en consonancia com la invisibilidade de lo indígena en la moderna esfera pública boliviana. En esta línea, recordamos las palabras del sociólogo Jesús Flores Vásquez:

"El Estado boliviano negó desde su fundación su propia comunidad política, pues no reconoció como ciudadanos a los indígenas, lo que hubiera sido ya un inicio de la modernización: la igualdad abstracta (...). Fue sólo a partir de la derrota en la Guerra del Chaco cuando se entendió que había que incluir definitivamente a los indios, pero como bolivianos, esto es bajo el proyecto del mestizaje cultural, lo que fue otra vez una eliminación, esta vez simbólica, de los indios. Sólo a principios del siglo XXI se dio un grado general de autoconciencia plurinacional y de la necesidad de un proceso de descolonización" (VVAA, 2010, p.149). 
Tal y como hemos referido, nuestro análisis se centra en un grupo concreto de artistas bolivianos contemporáneos, que sin ser su objetivo prioritario, formulan actuales discursos sobre la cultura indígena. Estos artistas resignifican lo indígena y la etnicidad alejados de estereotipos y desde acomplejidades periféricas y en íntima conexión con sus autoconstrucciones y reencuentros personales. Desde este plano, se constituyen como agentes sociales de la diferencia desde las prácticas artísticas. Sus narrativas, se propagan por la esfera pública por el calado y permanencia de su legado artístico, en parte uma permanencia facilitada por las nuevas tecnologias y la organización de distintas bienales de Arte Contemporáneo no sólo en ámbito boliviano, sino dentro de contextualidades latinoamericana. De este modo se gesta y potencia su nuevo rol de líderes de opinión, desde su categoria de sujeto étnico para la diferencia.

\section{CONSIDERAÇÕES}

Desde mi formación académica inicial en Antropología, tiene su lógica mi interés en querer entender lo indígena y la etnicidad en los actuales contextos socioculturales. Este es el punto de arranque de este texto, si bien em realidade parte de una deuda disciplinar pendiente: visibilizar sin visiones etnocentristas europeístas estos conceptos. Si como dijo Connor "la nación se construye siempre a partir de una comunidad étnica" (Connor, W. 1994: 132), nunca he entendido los motivos de seguir reflexionando en los contextos europeístas de espaldas a la etnicidad.

También muchos de las gestiones y distribuciones museísticas actuales, nos recuerdan la necesidad de resignificar lo indígena, más allá de vencidos y colonizados, pero sin negar y dejar de percibir las geopolíticas múltiples y diversas de lo indígena. En ese continuar la reflexión antropológica, y reconociendo el valor de la investigación etnográfica, considero imprescindible una aproximación a la realidad actual de lo indígena desde "lo visual". Nuestras sociedades confluyen entre lo local y lo global y están selladas por la cultura visual. Es por ello, que es preciso abrir nuevas perspectivas reflexivas de lo indígena en Antropología y Sociología, creando puentes con la producción artística visual.

Dentro de la contextualización de este texto en Bolivia, aludo a puentes que ya están levantados y se divisan muchos otros nuevos en construcción. Al respecto referencio los puentes ya tendidos por Juan Fabbri o Alejandra Alarcón, entre una larga lista. 
Las narrativas audiovisuales de los diecinueve $\operatorname{artistas}^{8}$ citados al inicio de este texto refuerzan las tesis de ver al arte como un espacio de reflexión y de batalla simbólica. De ahí que pese a no priorizar de forma consciente - a diferencia de la obra pictórica boliviana del 1920-1950- hablar de lo indígena, se llegue a esos discursos de forma rizomática. Por otro lado, sus puntos de partida también se apartan de lo político: A partir de estos criterios podemos decir que, en cuanto al contenido, los artistas que hacen video-arte no se diferencian demasiado de aquellos que hacen arte dentro de las artes visuales contemporáneas, es decir, la mayor parte de las obras de video-arte reflexionan acerca del contexto social y cotidiano del artista sobre la base de una mirada particular, que sin embargo, muy pocas veces tiene un sentido claramente político. De hecho Alejandra Dorado, Roberto Unterlastaetter y en menor medida José Ballivián, son algunos de los escasos artistas cuyos trabajos aluden a contenidos políticos. No obstante, probablemente encontremos en otras obras implicaciones políticas, pero es a pesar de sus autores.

"Es como si éstos evitaran el tema del poder y sus connotaciones por la mala reputación que tiene aquí la política; cabe agregar que esta situación va a contramano de lo que suele caracterizar al video-arte latinoamericano en general, cuyo cuestionamiento al poder en el ámbito de lo público y lo privado ha sido, y es, constante. " (Ramiro Garavito, 2019 p.139).

No obstante, lo político no está circunscrito a la producción desde los centros de gobierno e instituciones políticas. Lo político alude también a la construcción de las subjetividades y de las intersubjetividades, por lo que de forma ineludible llegaremos, a la construcción de geopolíticas. Lo relevante es que ciertas prácticas videoartísticas abren nuevos procesos etnopolíticos de diferenciación, desde una óptica femenina y desde una conciencia que no rechaza su pasado, pero está alejado del dolor de las heridas y estragos de los procesos de colonización.

\section{REFERÊNCIAS}

CONNOR, W. (1994). Ethno-nationalism. The Quest for Understanding. Princeton University y Press, Nueva Jersey, Estados Unidos.

FRANCOVIC, Guillemo (1987). Los mitos profundos de Bolivia. Ed. Los Amigos del Libro. La Paz.

\footnotetext{
${ }^{8}$ Volvemos a recordar que se ha hecho una selección por cuestiones metodológica, pues se han quedado por nombrar muchos otros artistas bolivianos con producción en el video-arte.
} 
GUNDERMAN, H. (1997). Etnicidad, identidad étnica y ciudadanía en los países andinos y el norte de Chile, en Revista de Estudios Atacameños, no 13, pp.9-26.

HERNÁNDEZ, C. (2001). El indigenismo en diálogo. Publicaciones del Centro Atlántico de Arte Moderno de Las Palmas de Gran Canaria.

IDB, Between Past and Present Naionalist Tendencies in Bolivian Art 1925-1950.

Disponible en https://publications.iadb.org/publications/english/document/Between-Past-andPresent-Nationalist-Tendencies-in-Bolivian-Art-1925-1950.pdf

GARAVITO, Ramiro (2019). El invento arte. Textos escogidos 1998-2017. Edita Agencia Española de Cooperación Internacional para el Desarrollo y Galería KIOSKO, Bolivia.

MORALES, H. (2016). Etnopolítica atacameña: ejes de la diversidad. En Revista de Estudios Atacameños, $\mathrm{n}^{\circ}$ 53, pp.185-203.

PAZ, Valeria. (1998). Intromisiones femeninas en el arte boliviano de fines de los noventa: La obra de Guiomar Mesa, Erika Ewel y Valia Carvalho. Revista Ciencia y Cultura, (4), 69-74. Recuperado en 08 de junio de 2020, de http://www.scielo.org.bo/scielo.php?script=sci_arttext\&pid=S207733231998000200010\&lng=es\&tlng=es

VV.AA. (2010) El video arte en Bolivia. Aproximaciones teóricas y Videografía. La Paz. En https://proyectoidis.org/wp-content/uploads/2010/02/EL-VIDEO-ARTE-EN-BOLIVIA.pdf

Doctora en Sociología por la Universidad de Barcelona. Ha realizado trabajos de investigación en el Instituto de Estudios de Almería, en el Departamento de Cultura Popular de la Generalitat de Cataluña. Profesora invitada en la Université d'Amiens (Francia), en la Università Deglo Studi di Milano-Biccoca (Italia), en la Escuela de Comunicación Social de Lisboa y en la Universidad Nacional de Córdoba (Argentina), entre otros centros. Actualmente es profesora de la Universidad Rey Juan Carlos

(Madrid).

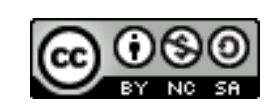

Esta obra está licenciada com uma Licença

Creative Commons Atribuição-NãoComercial-CompartilhaIgual 4.0 Internacional 